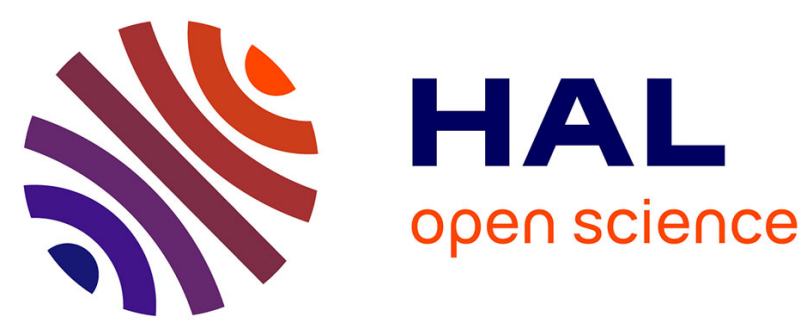

\title{
HtrA1 is a potential predictor of response to cisplatin-based combination chemotherapy in gastric cancer
}

\author{
Vincenzo Catalano, Pasquale Mellone, Alfredo d'Avino, Viji Shirdhar, \\ Mariapia Staccioli, Francesco Graziano, Paolo Giordani, David Rossi, \\ Annamaria Baldelli, Paolo Alessandroni, et al.
}

\section{To cite this version:}

Vincenzo Catalano, Pasquale Mellone, Alfredo d'Avino, Viji Shirdhar, Mariapia Staccioli, et al.. HtrA1 is a potential predictor of response to cisplatin-based combination chemotherapy in gastric cancer. Histopathology, 2011, 58 (5), pp.669. 10.1111/j.1365-2559.2011.03818.x . hal-00627935

\section{HAL Id: hal-00627935 https://hal.science/hal-00627935}

Submitted on 30 Sep 2011

HAL is a multi-disciplinary open access archive for the deposit and dissemination of scientific research documents, whether they are published or not. The documents may come from teaching and research institutions in France or abroad, or from public or private research centers.
L'archive ouverte pluridisciplinaire HAL, est destinée au dépôt et à la diffusion de documents scientifiques de niveau recherche, publiés ou non, émanant des établissements d'enseignement et de recherche français ou étrangers, des laboratoires publics ou privés. 


\section{Histopathology}

\section{HtrA1 is a potential predictor of response to cisplatin-based combination chemotherapy in gastric cancer}

\begin{tabular}{|c|c|}
\hline Journal: & Histopathology \\
\hline Manuscript ID: & HISTOP-04-10-0223.R1 \\
\hline Wiley - Manuscript type: & Original Article \\
\hline $\begin{array}{r}\text { Date Submitted by the } \\
\text { Author: }\end{array}$ & $15-J u l-2010$ \\
\hline Complete List of Authors: & $\begin{array}{l}\text { Catalano, Vincenzo; Ospedale San Salvatore, Medical Oncology } \\
\text { Mellone, Pasquale; Second University of Naples, Biochemistry } \\
\text { D'Avino, Alfredo; Second University of Naples, Biochemistry } \\
\text { Shirdhar, Viji; Mayo Clinic Cancer Center, Experimental Medicine } \\
\text { Staccioli, Mariapia; Ospedale San Salvatore, Medical Oncology } \\
\text { Graziano, Francesco; Ospedale San Salvatore, Medical Oncology } \\
\text { Giordani, Paolo; Ospedale San Salvatore, Medical Oncology } \\
\text { Rossi, David; Ospedale San Salvatore, Medical Oncology } \\
\text { Baldelli, AnnaMaria; Ospedale San Salvatore, Medical Oncology } \\
\text { Alessandroni, Paolo; Ospedale San Salvatore, Medical Oncology } \\
\text { Santini, Daniele; Campus Biomedico University, Oncology } \\
\text { Lorenzon, Laura; La Sapienza University, Surgery } \\
\text { Testa, Enrico; Urbino Hospital, Oncology } \\
\text { D'Emidio, Silvia; Ospedale San Salvatore, Medical Oncology } \\
\text { De Nictolis, Michele; Ospedale San Salvatore, Medical Oncology } \\
\text { Muretto, Paolo; Ospedale San Salvatore, Medical Oncology } \\
\text { Luzi Fedeli, Stefano; Ospedale San Salvatore, Medical Oncology } \\
\text { Baldi, Alfonso; Second University of Naples, Biochemistry, Sect } \\
\text { Pathology }\end{array}$ \\
\hline Keywords: & chemoresistance, chemotherapy, htra1, cisplatin, gastric cancer \\
\hline
\end{tabular}

\section{scholarONE \\ Manuscript Central}




\section{HtrA1 a potential predictor of response to cisplatin-based combination chemotherapy in gastric cancer}

Vincenzo Catalano1, Pasquale Mellone2, Alfredo d'Avino2, Viji Shridhar3, Mariapia Staccioli4, Francesco Graziano1, Paolo Giordani1, David Rossi1, Annamaria Baldelli1, Paolo Alessandroni1, Daniele Santini5, Laura Lorenzon7, Enrico Testa6, Silvia D’Emidio8, Michele De Nictolis4, Paolo Muretto4, Stefano Luzi Fedeli1, Alfonso Baldi2

1Medical Oncology, Azienda Ospedaliera "Ospedale San Salvatore”, Pesaro, Italy 2Deptartment of Biochemistry, Second University of Naples, Naples, Italy 3Department of Laboratory Medicine and Experimental Pathology, Mayo Clinic Cancer Center, Rochester, Minnesota, U.S.A.

4Department of Histopathology, Azienda Ospedaliera "Ospedale San Salvatore", Pesaro, Italy

5Department of Medical Oncology, University Campus-Biomedico, Rome, Italy 6Medical Oncology, Urbino Hospital, Urbino, Italy

7Department of Surgery "A", Second Faculty of Medicine, "La Sapienza" University, Rome, Italy

8Data Management, Medical Oncology, Azienda Ospedaliera "Ospedale San Salvatore", Pesaro, Italy 


\section{Corresponding author:}

Prof. Alfonso Baldi

Dept. Biochemistry, sect. Pathology, Second University of Naples, Via I. Armanni 5, 80138 Naples, Italy

Phone: +390815666003

Email: alfonsobaldi@tiscali.it

Running title: HtrA1 predicts chemoresistance in gastric cancer

Key words: chemoresistance, chemotherapy, cisplatin, gastric cancer, HtrA1 


\begin{abstract}
Aims. HtrA1 is a member of the HtrA (High-temperature-requirement) family of serine proteases. HtrA1 plays protective role in various malignancies due to its tumour suppressive properties. This study was performed to determine HtrA1 expression as a predictor of chemoresponse in patients with advanced gastric cancer.
\end{abstract}

Methods and Results. HtrA1 expression was determined by immunohistochemistry on specimens of primary gastric cancer from 80 patients treated consecutively with cisplatin-based combination chemotherapy. Response to chemotherapy was assessed according to RECIST criteria. Our population consisted of M/F 51/29; median age 64 years (range, 32-82). A complete or partial response was observed in $71.4 \%(95 \% \mathrm{Cl}, 54.7-88.2), 66.7 \%(95 \% \mathrm{Cl}, 47.8-85.5)$, and $28.6 \%(95 \mathrm{Cl}, 11.8-$ 45.3) of tumours showing high, medium, and low HtrA1 expression, respectively. A statistically significant association between HtrA1 expression and the clinical response was observed $(p=0.002)$. The median overall survival for patients with high/medium expression was 17 months compared to 9.5 months for patients with low HtrA1 expression $(p=0.037)$.

Conclusions. Identification of HtrA1 in gastric cancer prior to chemotherapy indicates that levels of HtrA1 could be used to predict response to platinum-based combination therapies. Further assessment of HtrA1 expression is highly warranted in large, prospective studies. 


\section{Introduction}

Despite its decreasing prevalence, gastric carcinoma is still one of the major causes of cancer death worldwide.1 Many patients present at diagnosis with unresectable disease, 1,2 and also patients undergoing pathological $\mathrm{R} 0$ resection will probably relapse. For advanced gastric cancer, evidence supports the use of palliative chemotherapy with the aims of improving symptoms, quality of life, and possibly prolonging survival. Several chemotherapeutic agents are considered active in advanced gastric cancer and many combination chemotherapy regimens have been developed in the hopes of improving response rate and overall survival. Unfortunately, the benefits of combination chemotherapy have been modest.3 No globally accepted standard regimen has yet been established. The combination of 5-fluorouracil (5-FU) and cisplatin (CDDP) is generally accepted as the mainstay chemotherapy for gastric cancer patients. 2 Response rates with regimens containing CDDP are in the range of $25-45 \%$ and median overall survival rarely exceeds 11 months.2,4,5 In Europe, 5-FU has been replaced successfully by capecitabine in combination with CDDP, 5 whereas in Japan, $\mathrm{S}-1$, another oral fluoropyrimidine, plus CDDP is the most reasonable first-line standard chemotherapy based on recent randomised studies.6,7

Because of the notable toxicity of chemotherapy and the limited survival time for some patients with advanced gastric cancer, it would be useful to select those patients whose tumours will be sensitive to chemotherapy in order to avoid treatment-related toxicity in non-responding patients. 
While patients initially respond to CDDP, most patients develop resistance. The mechanisms leading to CDDP resistance include intracellular and extra-cellular changes that interfere with the ability of DNA damage signals to activate the apoptotic machinery, alter expression of several key apoptotic regulators, promote drug metabolism, decrease cellular drug accumulation, and increase repair of DNA adducts.8-10 At the present time, there are no clinically accepted molecular markers that can univocally predict the sensitivity or resistance of gastric cancer against chemotherapeutic agents.

The HtrA family of serine proteases was initially identified in E. coli by two phenotypes of null mutants that were unable to grow at elevated temperatures (HtrA for High temperature requirement),11 or failed to digest misfolded protein in the periplasm (DegP).12 Subsequently, homologues of HtrA/DegP have been described in a variety of species, including Gram-negative and -positive bacteria, plants and mammals. Until now, four human homologues of E. coli HtrA have been identified: HtrA1 (L56 or PRSS11),13,14 HtrA2/Omi,15,16 HtrA3 (PRSP)17 and HtrA4. The HtrA family of serine protease appears to be involved in several important biological mechanisms in mammals, such as growth, apoptosis, arthritis, embryogenesis, neurodegenerative and neuromuscular disorder, and cancer.18 HtrA1 has a widespread pattern of expression, and its level in human tissues is modulated both in tissues with different physiological activities.19-21 Data from our group indicate that HtrA1 acts as a tumour suppressor-like when over-expressed in cancer cell lines.22,23 Consistently, meta-analyses of publicly available microarray data from Oncomine.org indicate that HtrA1 is down-regulated and shows allelic 
imbalance in cancer of diverse origins, 18 and it has been found down-regulated by immunohistochemistry in different cancer histotypes.22,24,25 We also showed that HtrA1 expression is regulated by chemotherapeutic drugs. Notably, in preliminary studies we have shown that expression of HtrA1 primary tumours could be associated with better response to CDDP-based combination chemotherapy in ovarian cancer and gastric cancer, acting as an endogenous mediator of CDDP in cancer cells. Indeed, $\mathrm{HtrA} 1$ is activated during drug treatment in vitro, and active $\mathrm{HtrA} 1$ increases caspase $3 / 7$ activity and participates in chemotherapy-induced cytotoxicity. 26

We planned the present expanded investigation in metastatic gastric cancer for confirming our preliminary findings. 


\section{Materials and Methods}

Patients and treatment

This is a translational study which included 80 consecutive and unselected patients with recurrent or metastatic gastric cancer who underwent first-line CDDP-based combination chemotherapy at two oncology departments (Pesaro, Urbino). Patients were enrolled in prospective multi-institutional phase II studies, where CDDP was used in weekly combination regimens at a dose of $35-40 \mathrm{mg} / \mathrm{m} 2,27-29$ or in bi-weekly combination regimens at a dose of $50 \mathrm{mg} / \mathrm{m} 2.30,31$ For all these patients, tumour tissues were available at the Institute of Pathology and fully assessable for immunohistochemistry analyses. The medical and pathologic reports of these patients were examined in details for age and gender of the patients. The tumour site, histological subtype, grade, starting date of chemotherapy, first-line regimen used, response rate to first-line CDDP-based chemotherapy, date of first disease progression, and patient survival were analyzed.

All radiology studies were reviewed for confirming the treatment outcomes and defining response according to Response Evaluation Criteria in Solid Tumours (RECIST) guidelines.32 In the case of local relapse, objective response was assessed combining findings from both CT scan of the abdomen and endoscopy, including a new biopsy of the tumour, if still visible, or a biopsy of the area originally involved by the tumour. Patients were followed until the earliest of the following: their date of death, the date they were last known to be alive, or the end of the follow-up period on $31^{\text {st }}$ December 2008. Observations were censored at either the 
date of last known follow-up or the end date of the follow-up period if death had not occurred.

\section{Immunohistochemistry}

Tissues from surgical resection specimens of gastric cancer were obtained for each of the 80 patients. A minimum of 2 and a maximum of 4 sections for each tumour were analyzed. Sections from each specimen were cut at $5 \mu \mathrm{m}$, mounted on glass and dried overnight at $37^{\circ} \mathrm{C}$. All sections were then deparaffinized in xylene, rehydrated through a graded alcohol series and washed in phosphatebuffered saline (PBS). PBS was used for all subsequent washes and for antibody dilution. Endogenous peroxidase activity was blocked by $5 \%$ hydrogen peroxide. For immunohistochemistry, tissue sections were heated twice in a microwave oven for 5 min each at $700 \mathrm{~W}$ in citrate buffer $(\mathrm{pH} \mathrm{6})$ and then processed with the standard streptavidin-biotin-immunoperoxidase method (DAKO Universal Kit, DAKO Corp., Carpinteria, CA, USA). Anti-HtrA1 polyclonal antibody was used as previously described.22 Diaminobenzidine was used as the final chromogen, and hematoxylin as the nuclear counterstain. Negative control experiments for each tissue section were performed in the absence of the primary antibody. Positive controls included in each experiment consisted of tissue previously shown to express the antigen of interest. Three observers (A.B., P.M., and L.L.), blinded to treatment conditions, evaluated the staining pattern of the proteins separately and quantified HtrA1 expression in each specimen by scanning the entire section and estimating the number of positive cells at the high-power-field 10X20 and 
described as: low (less than $1 \%$ of positive cells); medium (from $1 \%$ to $20 \%$ of positive cells); and high (more than $20 \%$ of positive cells). The level of concordance for the final scores, expressed as the percentage of agreement between the observers, was 95\% (76 over 80 cases). In the remaining four specimens, the score was obtained after collegial revision and agreement. This protocol of quantification for HtrA1 has been set up and successfully used by our research group in several scientific investigations.19,22-23,25-26

\section{Statistical analysis}

The primary endpoint of the present analysis was the association between HtrA1 expression and tumour response. Additional analyses were addressed to time-toprogression (TTP) and overall survival (OS). The association between the expression of HtrA1 expression and chemoresponse was assessed using the $x^{2}$ test, or the Fisher's exact test where appropriate. TTP was calculated from the starting date of first-line chemotherapy to the date of progression (per investigator assessment), or death from any cause. OS was calculated from the starting date of first-line chemotherapy until death of any cause, or censored at last follow-up visit. Survival data were analyzed using the Kaplan-Meier product-limit method.33 Comparison of survival curves were performed using log-rank test. A multivariate analysis using the stepwise Cox proportional hazards regression modeling was performed considering those factors with prognostic significance in the univariate analysis. $P$ values $<0.05$ were considered statistically significant and all $P$ values 
correspond to two-sided significance tests. Approval of the study was obtained from the local research and ethics committee. 


\section{Results}

The characteristics of patients and the detailed chemotherapy protocols included are shown in Tables 1 and 2. The group consisted of 51 males and 29 females (mean age, 64 years; range, 32-82 years). All patients underwent total or subtotal gastrectomy. Fifty-nine patients received a gastrectomy with curative intent and 21 a palliative gastrectomy (surgical treatment in the presence of at least one metastatic site of disease). Six patients received adjuvant chemotherapy. Fifty-one patients received CDDP in a weekly schedule of combination chemotherapy,27-29 and 29 patients received CDDP in a bi-weekly schedule of combination chemotherapy.30-31 As shown in Table 2, there was no difference in treatment outcomes between the two groups. Following first-line chemotherapy, 15 patients showed a complete response, 29 patients a partial response, 19 patients a stabilization of disease, and 17 patients had a progression of disease, for an overall chemotherapy response rate of $55.0 \%(95 \% \mathrm{CI}, 44.1-65.9)$. At present, 10 patients are still alive with a median follow-up of 8.6 years (range, 5.5-10.6 years).

\section{HtrA1 expression analysis and response}

Low HtrA1 expression was identified in 28 (35\%) patients, medium HtrA1 expression in $24(30 \%)$ patients, and high HtrA1 expression in 28 (35\%) patients. Representative staining intensities are shown in Figure 1A-B-C. We did not find any significant association between $\mathrm{Htr} A 1$ expression and clinicopathological characteristics, such as age, sex, tumour site, Lauren classification, histological grade, vascular or lymphatic invasion, lymph node metastasis (data not shown), 
and different CDDP-based regimens (Table 2). A complete or partial response was observed in the $71.4 \%(95 \% \mathrm{Cl}, 54.7-88.2)$ of tumours that had high HtrA1 expression, in the $66.7 \%(95 \% \mathrm{Cl}, 47.8-85.5)$ of tumours with medium HtrA1 expression, and in the $28.6 \%(95 \mathrm{Cl}, 11.8-45.3)$ of tumours with low $\mathrm{HtrA} 1$ expression (Table 3). Response to first-line platinum containing regimens was significantly different between the groups (Table 3). When considering patients with high and medium $\mathrm{HtrA} 1$ expression as a group, $69.2 \%(95 \% \mathrm{Cl}, 56.6-81.7)$ of patients with high/medium HtrA1 expression responded to chemotherapy compared to $28.6 \%(95 \% \mathrm{Cl}, 11.8-45.3)$ of patients with low HtrA1 expression ( $p=$ 0.001). The odds ratio for responders to first-line CDDP-based combination chemotherapy in the cohort with high and medium levels of HtrA1 was 5.62 (95\% $\mathrm{Cl}, 2.05-15.43 ; p=0.0008)$. Clinically determined response rate was not related to any other clinicopathological factors.

\section{HtrA1 expression and survival}

The median TTP for all patients was 5.8 months (range, 2-104+), and the median survival time among all cases was 12.5 months, with 1-year and 2-years overall survival of $53.8 \%$ and $26.2 \%$, respectively.

The secondary endpoint was the association between HtrA1 expression and survival outcomes. Likely due to the relative small sample size, no differences in TTP and OS were found between groups with low, medium, and high HtrA1 expression levels (data not shown). However, considering patients with high/medium HtrA1 expression as a group, they showed longer TTP than patients 
with low HtrA1 expression (7.5 months and 4.6 months, respectively). The HR for risk of progression for patients with high and medium HtrA1 expression compared to low HtrA1 expression was $0.52(95 \% \mathrm{Cl}, 0.29-0.93 ; p=0.027)$ (Figure 2). Similarly, patients with high/medium HtrA1 expression had longer survival than patients with low $\mathrm{HtrA} 1$ expression (17.0 months and 9.5 months; $\mathrm{HR}=0.55 ; 95 \%$ $\mathrm{Cl}, 0.32-0.96, \mathrm{p}=0.037)$. The survival curves of low and high/medium HtrA1 expression are shown in Figure 3.

Univariate and multivariate analysis

Univariate analysis (Table 4) identified both age and number of metastatic sites as two other variables in addition to HtrA1 expression as being associated with prolonged survival rates. Multivariate regression analysis included the 3 variables that were found to have prognostic significance in univariate analysis in 80 patients. The Cox proportional regression analysis revealed that only the number of metastatic sites had a significant impact on survival, whereas age and HtrA1 expression were of border-line significance (Table 5). 


\section{Discussion}

Gastric cancer is still an incurable disease. Despite advances in chemotherapeutic intervention, only $40-45 \%$ of the patients receiving palliative chemotherapy may achieve a response. CDDP has a broad range of activity in malignant disease and is used to treat many types of cancer, including gastric cancer. Unfortunately, response rate to first-line CDDP-based chemotherapy rarely exceeds $45 \% .2$ The mechanism of resistance to CDDP-based regimens is multifactorial, including decrease drug uptake into the cell, increased drug inactivation, and increased DNA repair.34

Predictive markers of chemoresponse are potentially useful to select those patients who may respond favourably to CDDP therapy and spare patients who can be predetermined not to respond to such treatment. For example, in colorectal cancer patients, k-ras status is used as a predictive marker of response to EGFR-targeted agents. For many years researchers have focused attention on many potentially related molecular markers in determining the response to traditional chemotherapeutic agents. However, due to conflicting results it has not been easy to derive a marker (or a set of markers) of response to a particular treatment. Better and more accurate definition of the biological characteristics of the tumour in the individual level is needed, especially in the new era of molecular agents that target a specific biological pathway that is activated in a certain tumour. Recently, the addition of trastuzumab, a HER-2 directed drug, to standard chemotherapy allowed patients live longer than patients receiving chemotherapy alone.35 The phase III ToGA trial enrolled 594 patients whose tumours showed elevated levels 
of the protein HER-2. Patients who received trastuzumab plus chemotherapy (CDDP and capecitabine or 5-fluorouracil) had a median survival of 13.8 months, compared with 11.1 months for those who received chemotherapy alone. This translated into a $26 \%$ reduction in the rate of death. 35 Trastuzumab is the first targeted drug to improve overall survival for patients with gastric cancer in a phase III trial. These results, together with those from ongoing phase III trials including other biological agents, could be further improved in the presence of markers predicting efficacy of chemotherapy, as for CDDP-based therapy. HtrA1 may serve as surrogate marker of response to CDDP treatment patients with metastatic gastric cancer. The assessment of this marker by immunohistochemistry on gastric tumour samples is able to select nearly two third of responding patients. By analyzing other parameters that may be important for CDDP-based therapy regimens, for example the pathway of nucleotide excision repair36 and the mismatch repair pathway, 37 it should be possible to refine therapy prediction by defining a panel of predictive markers based on the combination of different parameters.

Chemotherapy response is highly complex, depending on tumour-specific characteristics as well as on constitutional genetic factors of the individual patient. Thus, it is unlikely that only one specific parameter will be found that will precisely predict therapy response for all patients. Available data on tumour biological markers are promising, but all of them arise from retrospective studies, generally including a small number of patients. Well designed, prospective trials are 
warranted in order to have a validated chemosensitivity predictive method which can change the target approach from a general to an individual treatment strategy. One could presume that immunohistochemical evaluation of some markers may provide reproducible reliable information that could guide the therapeutic strategy. Identification of markers to predict chemotherapeutic response and subsequent survival could help to individualize cancer therapy and improve treatment outcomes.

The bacterial serine-protease HtrA, also known as DegP, is a heat shock-induced envelope-associated serine protease.11,12 HtrA1, a member of the HtrA family of serine proteases, has been recently characterized for its effects on melanoma and ovarian cancer cells as a tumour suppressor-like protein.22,23 Recent data have also shown that $\mathrm{HtrA} 1$ acts as an endogenous modulator of CDDP-induced cytotoxicity.26

The aim of our study was to determine if response to CDDP-based combination treatments is associated with increased HtrA1 expression in gastric cancer. Our results indicate that high or medium HtrA1 expression was significantly correlated with response to first-line CDDP-containing regimens. Nearly $70 \%$ of cases with high and medium HtrA1 expression achieved a clinical response (complete or partial response) compared to less than $30 \%$ of patients whose tumours had low HtrA1 expression. The correlation between HtrA1 levels and response to first-line CDDP-based chemotherapy was of high statisticall significance $(p=0.002)$. The result of our present study encompassing 80 gastric carcinomas compares favourably with our preliminary report on ovarian and gastric cancer patients.26 In 
this study we have assessed HtrA1 expression in primary gastric tumours. Given the possible different expression of $\mathrm{Htr} A 1$ between primary tumours and metastatic sites, in future studies the assessment of HtrA1 levels from metastatic sites could be an interesting issue for better characterizing the clinical role of this factor. We also found HtrA1 expression to predict prolonged TTP and improved survival among CDDP-treated patients with gastric cancer. The median TTP was 7.5 months and 4.6 months $(p=0.027)$ for the high/medium expression group and low HtrA1 expression group, respectively. Additionally, median overall survival was 17 months for patients whose tumours had high/medium levels of HtrA1 versus 9.5 months for patients with low expression, with a $45 \%$ risk reduction of death $(p=0.037)$. The results of this exploratory study are encouraging, but the limited sample size does not allow any firm conclusion on the prognostic role of HtrA1. Nevertheless, it seems a strong candidate to be analyzed in large, prospective, independent series.

Our group has demonstrated that HtrA1 protein may modulate CDDP-induced cytotoxity, and that loss of HtrA1 may result in a chemoresistance phenotype.26 The predictive role of HtrA1 for response to platinum chemotherapy has been also shown in human ovarian cancer cell lines.38 Additional studies in ovarian cancer has implicated HtrA1 as a predictor of response to platinum-based therapy.26 The mechanism of how HtrA1 confers CDDP sensitivity to gastric cancer is not currently understood. However, based on the previous reports, 18,26 we anticipate that HtrA1 may function in a serine protease dependent manner to confer sensitivity to CDDP in gastric cancer. Future studies will focus on this aspect using 
gastric cancer cell lines with and without HtrA1 expression. As a comparison, we also assessed p53 expression in the same cohort of patients. Unlike HtrA1, levels of p53 did not correlate to response or survival (data not shown).

In conclusion, our data show that HtrA1 expression is a useful marker for response prediction to CDDP-containing combinations in gastric cancer. Tumours with high and medium HtrA1 expression show a better response to a CDDP-based combination chemotherapy than tumours with a low HtrA1 value. However, the predictive chemotherapy responsiveness of HtrA1 expression needs further evaluation in the context of large, prospective trials before accepting this marker for routinary use. 


\section{References}

1. Parkin DM, Pisani P, Ferlay J. Global Cancer Statistics. CA Cancer J. Clin. 1999;49:33-64.

2. Catalano V, Labianca R, Beretta GD, Gatta G, de Braud F, Van Cutsem E. Gastric cancer. Crit. Rev. Oncol. Hematol. 2009;71:127-164.

3. Wagner AD, Grothe W, Haerting J, Kleber G, Grothey A, Fleig WE. Chemotherapy in advanced gastric cancer: a systematic review and metaanalysis based on aggregate data. J. Clin. Oncol. 2006;24:2903-2909.

4. Van Cutsem E, Moiseyenko VM, Tjulandin S et al. Phase III study of docetaxel and cisplatin plus fluorouracil compared with cisplatin and fluorouracil as firstline therapy for advanced gastric cancer: A report of the V325 study group. J. Clin. Oncol. 2006;24:4991-4997.

5. Cunningham D, Starling N, Rao S et al. Capecitabine and oxaliplatin for advanced esophagogastric cancer. N. Engl. J. Med. 2008;58:36-46.

6. Boku N, Yamamoto S, Fukuda $\mathrm{H}$ et al. Fluorouracil versus combination of irinotecan plus cisplatin versus S-1 in metastatic gastric cancer: a randomised study. Lancet Oncol. 2009;10:1063-1069.

7. Narahara H, Koizumi W, Hara T et al. Randomized phase III study of S-1 alone versus S-1 + cisplatin in the treatment for advanced gastric cancer (the SPIRITS trial) SPIRITS: S-1 plus cisplatin vs S-1 in RCT in the treatment for stomach cancer. J. Clin. Oncol. 2007;25(Suppl 18):4514a. 
8. Fraser $M$, Leung $B$, Jahani-Asl A, Yan X, Thompson WE, Tsang BK. Chemoresistance in human ovarian cancer: the role of apoptotic regulators. Reprod. Biol. Endocrinol. 2003;1:66.

9. Sherman-Baust CA, Weeraratna AT, Rangel LB et al. Remodeling of the extracellular matrix through overexpression of collagen $\mathrm{VI}$ contributes to cisplatin resistance in ovarian cancer cells. Cancer Cell. 2003;3:377-386.

10. Borst $\mathrm{P}$, Rottenberg $\mathrm{S}$, and Jonkers $\mathrm{J}$. How do real tumors become resistant to cisplatin? Cell Cycle 2008;7:1353-1359.

11. Lipinska B, Sharma S, Georgopoulos C. Sequence analysis and regulation of the htrA gene of Escherichia coli: a sigma 32-independent mechanism of heatinducible transcription. Nucleic Acids Res. 1998;16:10053-10067.

12. Strauch KL, Beckwith J. An Escherichia coli mutation preventing degradation of abnormal periplasmic proteins. Proc. Natl. Acad. Sci. U.S.A. 1988;85:15761580.

13. Hu SI, Carozza M, Klein M, Nantermet P, Luk D, Crowl RM. Human HtrA, an evolutionarily conserved serine protease identified as a differentially expressed gene product in osteoarthritic cartilage. J. Biol. Chem. 1998;273:34406-34412.

14. Zumbrunn J, Trueb B. Primary structure of a putative serine protease specific for IGF- binding proteins. FEBS Lett. 1996;398:187-192.

15. Faccio L, Fusco C, Chen A, Martinotti S, Bonventre JV, Zervos AS. Characterization of a novel human serine protease that has extensive homology to bacterial heat shock endoprotease $\mathrm{HtrA}$ and is regulated by kidney ischemia. J. Biol. Chem. 2000;275:2581-2588. 
16. Gray CW, Ward RV, Karran E et al. Characterization of human HtrA2, a novel serine protease involved in the mammalian cellular stress response. Eur. J. Biochem. 2000;267:5699-5710.

17. Nie GY, Hampton A, Li Y, Findlay JK, Salamonsen LA. Identification and cloning of two isoforms of human high-temperature requirement factor $\mathrm{A} 3$ (HtrA3), characterization of its genomic structure and comparison of its tissue distribution with HtrA1 and HtrA2. Biochem. J. 2003;371:39-48.

18. Chien J, Campioni M, Shridhar V, Baldi A. HtrA serine proteases as potential therapeutics targets in cancer. Current Cancer Drug Target 2009; 9: 451-468.

19. De Luca A, De Falco M, Severino A et al. Distribution of the serine protease HtrA1 in normal human tissues. J. Histochem. Cytochem. 2003;51:1279-1284.

20. De Luca A, De Falco M, Fedele V et al. The serine protease HtrA1 is upregulated in the human placenta during pregnancy. J. Histochem. Cytochem. 2004;52:885-892.

21. De Luca A, De Falco M, De Luca L et al. Pattern of expression of HtrA1 during mouse development. J. Histochem. Cytochem. 2004;52:1609-1617.

22. Baldi A, De Luca A, Morini M et al. The HtrA1 serine protease is downregulated during human melanoma progression and represses growth of metastatic melanoma cells. Oncogene 2002;21:6684-6688.

23. Chien J, Staub J, Hu SI et al. A candidate tumor suppressor HtrA1 is downregulated in ovarian cancer. Oncogene 2004;23:1636-1644.

24. Esposito V, Campioni M, De Luca A et al. Analysis of HtrA1 serine protease expression in human lung cancer. Anticancer Res. 2006;26:3455-3459. 
25. Baldi A, Mottolese M, Vincenzi B et al. The serine protease HTRA1 is a novel prognostic factor for human mesothelioma. Pharmacogenomics 2008;9:10691077.

26. Chien J, Aletti G, Baldi A et al. Serine protease HtrA1 modulates chemotherapy-induced cytotoxicity. J. Clin. Invest. 2006;116:1994-2004.

27. Cascinu S, Labianca R, Alessandroni P et al. Intensive weekly chemotherapy for advanced gastric cancer using fluorouracil, cisplatin, epi-doxorubicin, 6Sleucovorin, glutathione, and filgrastim: a report from the Italian Group for the Study of Digestive Tract Cancer. J. Clin. Oncol. 1997;15:3313-3319.

28. Cascinu S, Graziano F, Barni S et al. A phase II study of sequential chemotherapy with docetaxel after the weekly PELF regimen in advanced gastric cancer. A report from the Italian group for the study of digestive tract cancer. Br. J. Cancer 2001;84:470-474.

29. Graziano F, Santini D, Testa E et al. A phase II study of weekly cisplatin, 6Sstereoisomer leucovorin and fluorouracil as first-line chemotherapy for elderly patients with advanced gastric cancer. Br. J. Cancer 2003;89:1428-1432.

30. Cascinu S, Baldelli AM, Catalano V et al. Infusional 5-fluorouracil, cisplatin and mitomycin $\mathrm{C}$ in advanced gastric cancer: a low cost effective regimen. Br. J. Cancer 2002;86:213-217.

31. Cascinu S, Labianca R, Catalano V et al. Pegylated liposomal doxorubicin, 5fluorouracil and cisplatin versus mitomycin-C, 5-fluorouracil and cisplatin for advanced gastric cancer: A randomised phase II trial. J. Clin. Oncol. 2008;26(Suppl. 20):13521a. 
32. Therasse P, Arbuck SG, Eisenhauer EA et al. New guidelines to evaluate the response to treatment in solid tumors. European Organization for Research and Treatment of Cancer, National Cancer Institute of the United States, National Cancer Institute of Canada. J. Natl. Cancer Inst. 2000;92:205-216.

33. Kaplan EL, Meier P. Non parametric estimation from incomplete observations. J. Am. Stat. Assoc. 1958;53:457-481.

34. Martin LP, Hamilton TC, Schilder RJ. Platinum resistance: the role of DNA repair pathways. Clin. Cancer Res. 2008;14:1291-1295.

35. Van Cutsem E, Kang $\mathrm{Y}$, Chung $\mathrm{H}$ et al. Efficacy results from the ToGA trial: $\mathrm{A}$ phase III study of trastuzumab added to standard chemotherapy (CT) in firstline human epidermal growth factor receptor 2 (HER2)-positive advanced gastric cancer (GC). J. Clin. Oncol. 2009;27(Suppl. 18):LBA4509.

36. Rabik CA, Dolan ME. Molecular mechanisms of resistance and toxicity associated with platinating agents. Cancer Treat Rev 2007; 33: 9-23.

37. Aebi S, Kurdi-Haidar B, Gordon R et al. Loss of DNA mismatch repair in acquired resistance to cisplatin. Cancer Res. 1996;56:3087-3090.

38. Komatsu M, Hiyama K, Tanimoto K et al. Prediction of individual response to platinum/paclitaxel combination using novel marker genes in ovarian cancers. Mol. Cancer Ther. 2006;5:767-775. 
Aknowledgments: This work was supported by FUTURA-onlus and Second University grants to A.B. 


\section{Legend to Figures}

Figure 1. Immunohistochemical analysis of HtrA1 expression in primary gastric cancer. A: High HtrA1 expression (Avidin-Biotin Complex, original magnification 20X); B: Medium HtrA1 expression (Avidin-Biotin Complex, original magnification 20X); C: Low HtrA1 expression (Avidin-Biotin Complex, original magnification 20X)

Figure 2. Kaplan-Meier plotting for the time-to-progression of the 80 patients with gastric adenocarcinoma, stratified according to HtrA1 expression

Figure 3. Kaplan-Meier plotting for the cumulative 5-year survival of the 80 patients with gastric adenocarcinoma, stratified according to HtrA1 expression 
Table 1. Patient characteristics

\begin{tabular}{|c|c|}
\hline Characteristic & $\begin{array}{c}\text { Overall } \\
(n=80)\end{array}$ \\
\hline \multicolumn{2}{|l|}{ Sex } \\
\hline Male/Female & $51 / 29$ \\
\hline Median age, years (range) & $64(32-82)$ \\
\hline \multicolumn{2}{|l|}{ Previous surgery } \\
\hline Partial gastrectomy & 35 \\
\hline Total gastrectomy & 45 \\
\hline \multicolumn{2}{|l|}{ Primary tumor site } \\
\hline Proximal & 14 \\
\hline Body & 26 \\
\hline Distal stomach & 37 \\
\hline Anastomosis & 3 \\
\hline \multicolumn{2}{|l|}{ Histology } \\
\hline Adenocarcinoma & 64 \\
\hline Signet ring cell/Indifferentiated & 16 \\
\hline \multicolumn{2}{|l|}{ Lauren classification } \\
\hline Intestinal type & 43 \\
\hline Diffuse type & 37 \\
\hline \multicolumn{2}{|l|}{ Grading } \\
\hline Well-Moderately differentiated & 17 \\
\hline Low differentiated & 53 \\
\hline Missing & 5 \\
\hline \multicolumn{2}{|l|}{ Number of metastatic sites } \\
\hline 1 & 43 \\
\hline$\geq 2$ & 37 \\
\hline \multicolumn{2}{|l|}{ Stage of disease* } \\
\hline I & 3 \\
\hline$\| \mathrm{A}$ & 11 \\
\hline IIB & 12 \\
\hline IIIA & 10 \\
\hline IIIB & 18 \\
\hline IIIC & 5 \\
\hline IV & 21 \\
\hline \multicolumn{2}{|l|}{ Site of metastatic disease } \\
\hline Liver & 30 \\
\hline Peritoneum & 22 \\
\hline Lymph node & 37 \\
\hline Lung & 2 \\
\hline local relapse & 17 \\
\hline Other & 18 \\
\hline
\end{tabular}

*According to TNM Classification, $7^{\text {th }}$ Edition, 2009. 
Table 2. Overall response rate, HtrA1 expression, time-to-progression, and overall survival according to first-line cisplatin-based combination chemotherapy

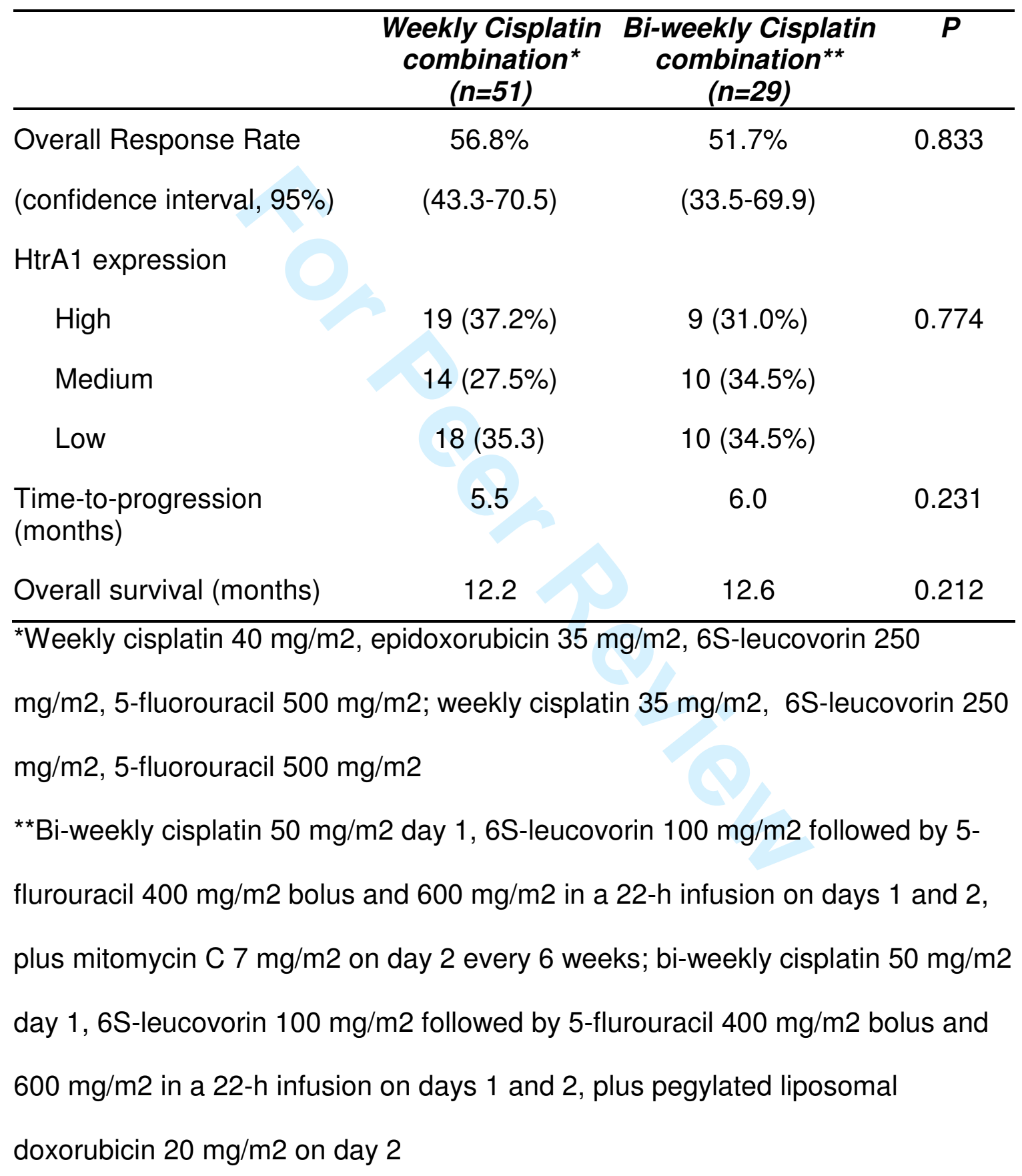


Table 4. Clinicopathological characteristics and their association with overall survival in 80 patients with metastatic gastric cancer

\begin{tabular}{|c|c|c|c|}
\hline Variable & $\mathbf{n}$ & $\begin{array}{l}\text { Median survival } \\
\text { (months) }\end{array}$ & $P$ value \\
\hline \multicolumn{4}{|l|}{$\overline{\text { Age }}$} \\
\hline$\leq 64$ & 40 & 19.0 & \multirow{2}{*}{0.026} \\
\hline$<64$ & 40 & 11.0 & \\
\hline \multicolumn{4}{|l|}{ Sex } \\
\hline Male & 51 & 12.5 & \multirow{2}{*}{0.479} \\
\hline Female & 29 & 13.4 & \\
\hline \multicolumn{4}{|l|}{ Lauren classification } \\
\hline $\begin{array}{l}\text { intestinal type } \\
\text { diffuse type }\end{array}$ & $\begin{array}{l}43 \\
37\end{array}$ & $\begin{array}{l}14.3 \\
11.8\end{array}$ & 0.344 \\
\hline \multicolumn{4}{|l|}{ Invasion } \\
\hline yes & 43 & 10.2 & \multirow{2}{*}{0.103} \\
\hline no & 37 & 16.1 & \\
\hline \multicolumn{4}{|l|}{ Grading } \\
\hline well/moderately differentiated & 17 & 14.4 & \multirow{2}{*}{0.675} \\
\hline low differentiated & 58 & 12.5 & \\
\hline \multicolumn{4}{|l|}{ Primary site } \\
\hline GEJ/cardias & 14 & 14.0 & \multirow{2}{*}{0.619} \\
\hline body/distal stomach & 63 & 12.5 & \\
\hline \multicolumn{4}{|l|}{ HtrA1 expression } \\
\hline high/medium & 52 & 16.8 & \multirow{2}{*}{0.037} \\
\hline Low & 28 & 9.5 & \\
\hline \multicolumn{4}{|l|}{ Number of metastatic sites } \\
\hline 1 & 43 & 15.6 & \multirow[t]{2}{*}{0.008} \\
\hline$\geq 2$ & 37 & 11.1 & \\
\hline \multicolumn{4}{|l|}{ Peritoneal carcinomatosis } \\
\hline yes & 22 & 11.5 & \multirow{2}{*}{0.294} \\
\hline no & 58 & 13.8 & \\
\hline \multicolumn{4}{|l|}{ Liver metastasis } \\
\hline yes & 30 & 11.5 & \multirow{2}{*}{0.920} \\
\hline no & 50 & 13.5 & \\
\hline
\end{tabular}

Abbreviation: GEJ= gastroesophageal junction. 
Table 5. Cox regression survival analysis of factors predicting survival time of patients with gastric cancers $(n=80)$

\begin{tabular}{lccc}
\hline Variable & Hazard ratio & $\begin{array}{c}\text { 95\% confidence } \\
\text { interval }\end{array}$ & $\boldsymbol{P}$ value \\
\hline Age & 1.58 & $0.97-2.58$ & 0.065 \\
$\quad \leq 64$ versus $>64$ & & & \\
HtrA1 expression: & 1.54 & $0.93-2.54$ & 0.089 \\
$\quad$ high/medium versus low & & & 0.024 \\
Number of metastatic sites & 2.53 & $1.13-5.65$ & \\
\hline 1 versus $\geq 2$ & & &
\end{tabular}



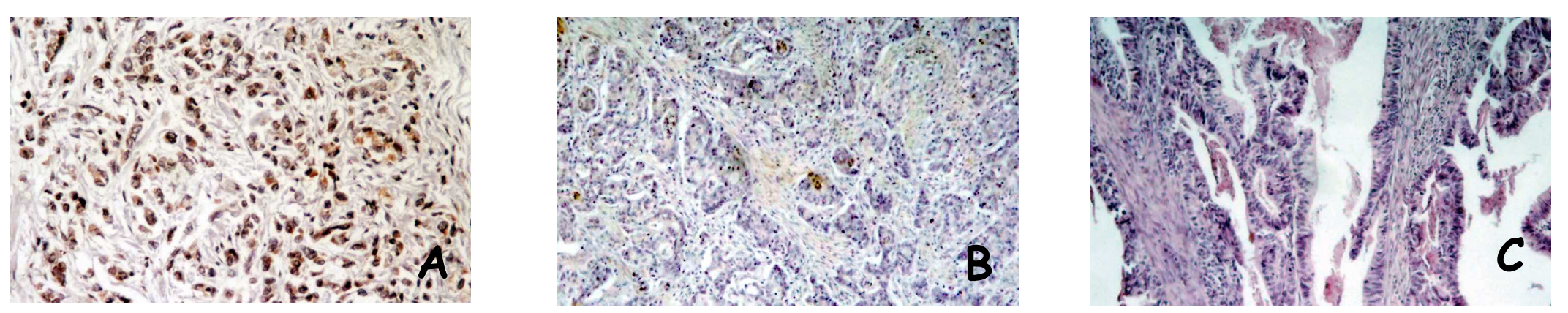


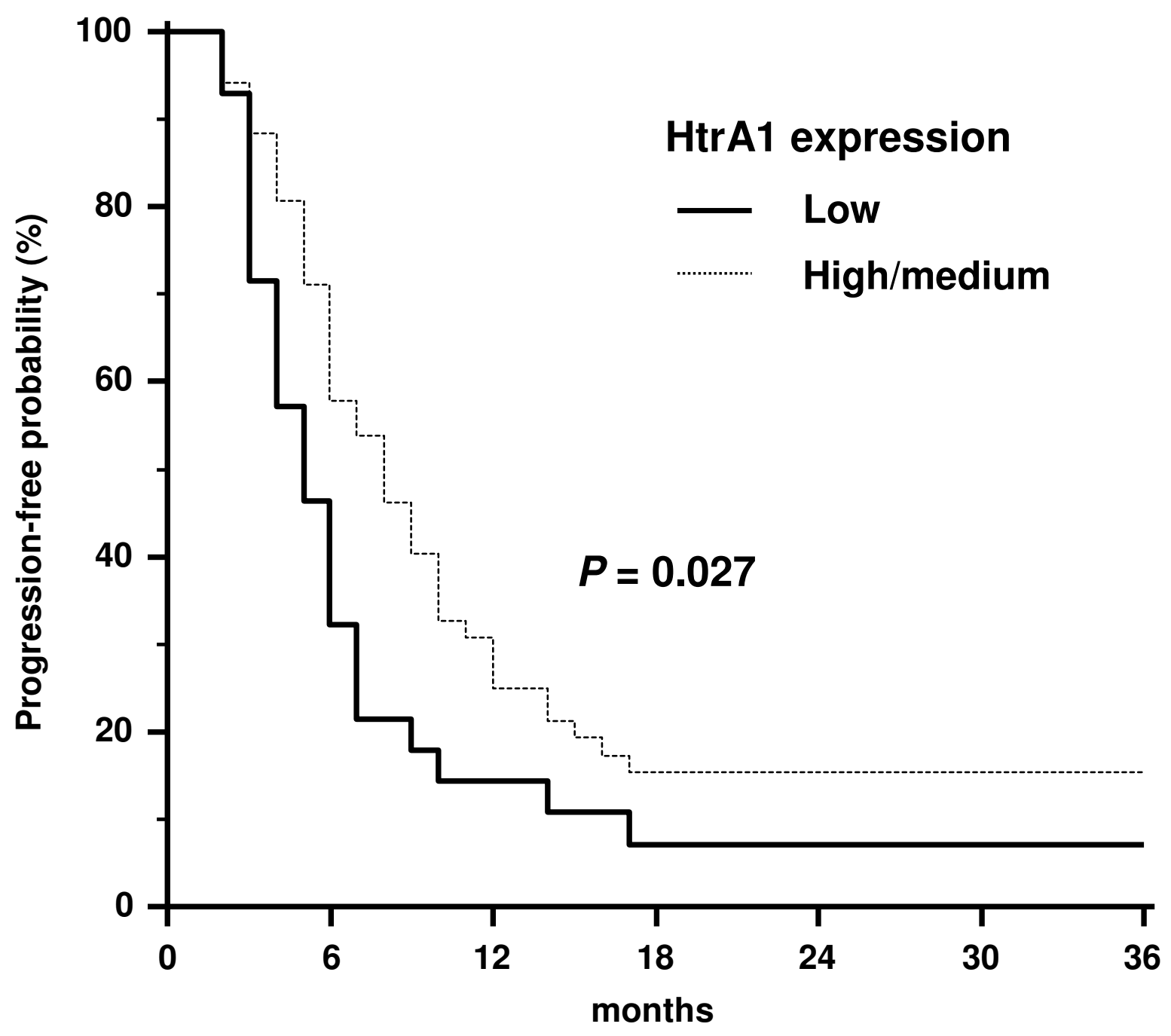




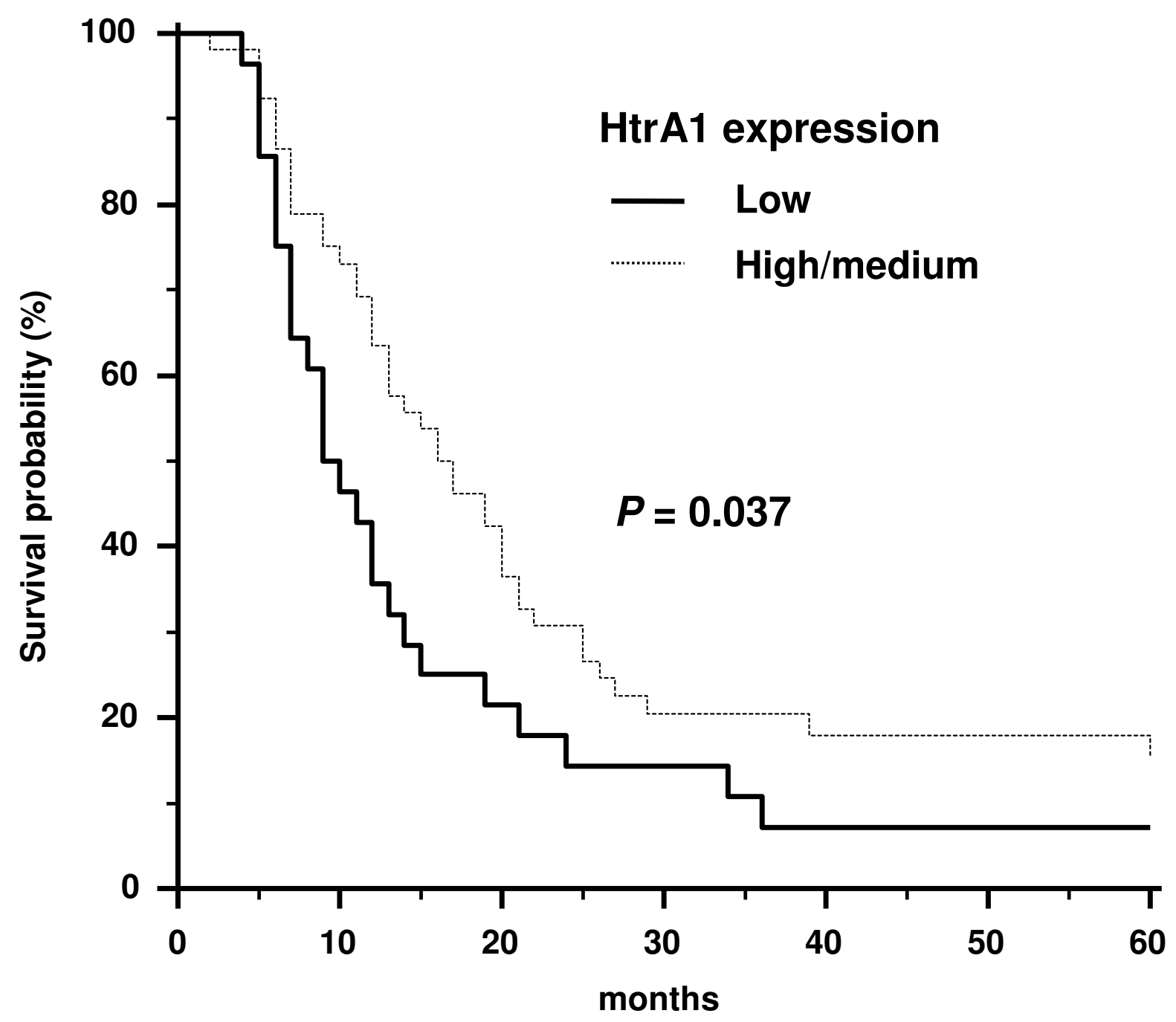

